ORIGINAL ARTICLE

\title{
Health Workforce Acquisition, Retention and Turnover in Southwest Ethiopian Health Institutions
}

\author{
Hailay Abrha Gesesew ${ }^{1,2}$, Bosena Tebeje ${ }^{3}$, Fessahaye Alemseged ${ }^{1}$, Waju Beyene ${ }^{4}$
}

ABSTRACT

BACKGROUND: Skill mix of health professionals, staff acquisition and turnover rate are among the major challenges for the delivery of quality health care. This study assessed the health workforce acquisition, retention, turnover rate and their intention to leave.

METHODS: A cross-sectional survey with quantitative and qualitative data collection methods was conducted in Jimma Zone health institutions. Five years records (September 2009-August 2014) were reviewed to determine the turnover rate. A total of 367 health professionals were included for the quantitative study. For the qualitaive study, all available and relevant health managers and administrative records in the selected health institutions were included. Descriptive and inferential analyses were done for the quantitative study. Thematic analysis was used for the qualitative component. RESULTS: A total of 367 health workers were incorporated for the quantitative study making a response rate of $87 \%$. The overall health workers' satisfaction was neutral (mean 3.3). In five years period, $45.9 \%$ staffs had left for a cause; $59.4 \%$ health professionals intended to leave. Being male (AOR =1.6, 95\% CI: 1.001-2.5), not knowing their overall satisfaction (AOR=0.5, 95\%CI: 0.2-0.8), below mean score of institutional satisfaction (AOR =1.7, 95\%CI: 1.06-2.7) and below mean score of organizational satisfaction (AOR=1.8, 95\%CI: 1.08-2.8) were independent predictors for intention to leave.

CONCLUSIONS: The overall health workers' satisfaction was marginally neutral. A considerable number of staffs had left, and more than half of the current staffs had an intention to leave. Thus, it is recommended that the responsible authorities should design strategies to improve the situation.

KEYWORDS: Health workforce, acquisition, retention, turnover, Ethiopia

DOI: http://dx.doi.org/10.4314/ejhs.v26i4.5

\section{INTRODUCTION}

Effective recruitment and retention of health workers has a vital contribution to mortality and morbidity reduction (1). There are different factors that hinder effective recruitment and retention of health professionals. Out-migration of doctors and nurses challenge to recruit and retain health professionals (2). The staff turnover can be described as the total movement of employees in and out of an organization (3). Staff turnover is an issues that organizations in many sub-Saharan country are currently facing, and it is a matter that is especially affecting the medical field. A research done by Ackinnon Partnership indicated that there is a relatively little movement out of the health sector (wastage is equivalent to around 2\% of the workforce) (1). Again, another research stated that turnover in Northern Ireland was 4\%, but in Scotland it was 7.8\% (4,5).

The problem is also a great headache to Ethiopia. There is a high turnover among the health professional staffs. A research done in Addis Ababa found that within the 20-year period of September 1991 to August 2011, a total of 120 faculty members left (6). Accordingly, it depicted

\footnotetext{
${ }^{1}$ Depertment of Epidemiology, Jimma University, Ethiopia

${ }^{2}$ Discipline of Public Health, Flinders University, Australia

${ }^{3}$ Depertment of Nursing, Jimma University, Ethiopia

${ }^{4}$ Depertment of Health Service Management, Jimma University, Ethiopia

Corresponding Author: Hailay Abrha Gesesew, Email: hailushepi@gmail.com
} 
that the overall turnover rate was $92.8 \%$. It also indicated that the rate in the most recent five years $(172 \%)$ is 8.5 times higher than the rate for the first five years $(20 \%)$. As within department mix is concerned, the study done in Addis Ababa showed that nursing (15.6\%), internal medicine (12.5\%), public health (10.4\%), pediatrics $(9.4 \%)$ and surgery $(9.4 \%)$ were among the top five departments where employment contracts were cut (7).

Turnover may not sometimes be measured directly. However, it can be addressed through intention to leave (8). Intention to leave is an expressed intention of employees leaving their current job in the near future (9). Organizational, individual and managerial issues are among factors affecting intention to leave (10-13).

On these issues, although some researchers attempted to conduct studies, most of them were only quantitative and were not in mixed institutions. This study assessed, qualitatively and quantitatively, the health workforce acquisition, retention, turnover rate and intention to leave in Jimma Zone health institutions.

\section{METHODS AND PARTICIPANTS}

The study was conducted in two selected hospitals named Jimma University Teaching Hospital (JUTH) and Limmu Genet Hospital (LGH) and three health centers called Jimma health center, Jimma Higher 02 health center and Menderakochi health center found in Jimma Zone, southwest Ethiopia. The zone is divided into 18 districts and one town administration with a total of 545 kebeles (lowest administrative unit) of which 515 are rural. The total projected population of the zone was $2,486,155$ of which $89.69 \%$ were rural inhabitants (14). Regarding health institutions, the zone has three governmental hospitals, 54 health centers and 117 health posts. Data for the study were collected from June to July 2014. A cross-sectional study design using both quantitative and qualitative methods was used. Quantitative method was employed to assess health care providers' views about their institution staff acquisition and retention activities. In addition, professional mix and staff turnover rate were assessed using quantitative method. Qualitative method was used to assess managers' views and records of managerial activities regarding staff acquisition and retention.

Health care providers working in hospitals and health centers in Jimma Zone were used as study population for assessing their views on staff acquisition and retention. Personnel administration records of the past five years in the health institutions were used for assessing staff turnover rate. Health managers and administrative records of hospitals and health centers in Jimma Zone were the population for assessing the existing staff acquisition and retention activities.

The sample size was determined by using sample determination formula for estimating single population proportion using the following assumptions: $95 \%$ confidence level, 50\% proportion of staff retention, $5 \%$ margin of error, and an expected $10 \%$ non-response. This totaled to give 422 samples. The total sample size was allocated to each facility proportionally for the stratified health institution in to hospitals and health centers. Furthermore, the sample of each facility was allocated according to types of professions proportional to population size. Finally, simple random sampling was used to select respondents from each type of profession. For the qualitative study, all available and relevant health managers and administrative records in the selected health institutions were included. The selection of managers and administrative records done was considering their possession of data necessary to answer study objectives.

Regarding the measurement, for the quantitative study on health workers, a pretested questionnaire was used to interview the health care providers where MPH holders took the responsibility. The questionnaire included questions to assess existing managerial processes related to staff acquisition and retention. For reviewing professional mix and staff turnover, a checklist was used. For the qualitative study, a checklist was used for document review, and an interview guide was employed for in-depth interview having contents similar to the questionnaire.

Quantitative data were entered, coded and analyzed using SPSS version 20. A descriptive analysis for each of the variables including 
frequency distribution and graphical presentation was carried out. Logistic regression was used to assess factors affecting intention to leave. Binary logistic regression was used to assess the crude association and detect candidate variables for multivariable logistic regression with P-value below 0.25. Multivariable logistic regression was applied to declare independently associated factors with cut-off P-value below 0.05. Data from the qualitative study were translated and transcribed to English and categorized accordingly to main thematic areas manually. The findings were presented in narratives in triangulation with the quantitative results. The responses were transcribed for every individual separately. And then, the transcribed data were categorized and analyzed thematically. Training of data collectors and supervisors, close supervision during data collection, making available the tool, checking completeness and consistency of filled checklist and performing exploratory analysis were the techniques used to assure the quality of the data.

Study participants provided informed consent before the commencement of each interview, and no personal identification was registered. There was no any financial compensation or provision for the study participants. Permission was obtained from JUSH and the study was approved by institutional review board (IRB) of college of health sciences at Jimma University, Southwest Ethiopia.

\section{RESULTS}

\section{Socio-demographic and economic} Characteristics of study participants: A total of 367 health workers were incorporated for the quantitative study making a response rate of $87 \%$. More than three-fourth $(77.4 \%)$ of the health workers were from JUTH followed by LGH accounting for $15.3 \%$ whereas Jimma Health Center contributed the least (2.2\%). Out of the total 367 participants, most $(57.2 \%)$ were males and their mean age was $28.18( \pm 7.36)$ years. The majority of the study participants were single $(56.7 \%)$, orthodox $(42 \%)$ and Oromo (61.9\%). In terms of education, almost half of the study participants were diploma holders followed by BSc degree holders while second degree graduates were the least in number (1.6\%). Nurses were the dominant staffs followed by midwifery and pharmacy constituting $67.8 \%, 7.9 \%$ and $6.3 \%$ respectively. Their median monthly income was 1917 Ethiopian Birr. Around $90 \%$ of them lived with more than five family members, and in terms of experience, the majority of them served below five years. Nearly $92 \%$ of the health workers were full timers and only $1.6 \%$ of them were employed on contractual basis. Regarding positions, 3.7\% had managerial positions (Table $1)$.

Staff Recruitment and Selection Process: Most of the staffs $(56.1 \%)$ were recruited by the District Health Office/Zonal Health Department/ Regional Health Bureau/Ministry of Health. Significant number $(34.9 \%)$ of staffs were also recruited via vacancy from the setting. The majority of the participants believed that the recruitment gave equal chance for all the potential applicants during employment. The study participants perceived that the recruiters were skill full and did have a plan to recruit. Some $17.4 \%$ of them described the selection process as not transparent. About $70.6 \%$ of health workers got an orientation on their duties and responsibilities (34.6\%) and were informed about their work $(28.3 \%)$. This was also supported by the qualitative study. Regarding established job requirements in their organizations, more than half $(54 \%)$ confirmed its presence and around $37 \%$ reported its presence in their hands. According to the indepth interviews with head of the institution and chief executive officer of the hospitals, the overall effectiveness of staff acquisition process was insufficient. The possible reasons were lack of budget, untimely replacement of resigned staffs, less interest of highly qualified staffs (MPH and specialty) and poor recruitment procedures. They tried to solve the problem by discussing with district/town health offices, working with available staffs by adding some incentives and using apparentship students. 
Table 1: Distribution of health workers by socio-demographic and economic characteristics in Jimma Zone health institutions, Southwest Ethiopia, $2014(\mathrm{n}=367)$

\begin{tabular}{|c|c|c|}
\hline Variable & Category & Number $(\%)$ \\
\hline \multirow[t]{5}{*}{ Health institution } & JUTH & $284(77.4)$ \\
\hline & LGH & $56(15.3)$ \\
\hline & Higher 2 health center & $10(2.7)$ \\
\hline & Mendera Kochi health center & $9(2.5)$ \\
\hline & Jimma health center & $8(2.2)$ \\
\hline \multirow[t]{2}{*}{ Sex } & Male & $210(57.2)$ \\
\hline & Female & $157(42.8)$ \\
\hline Age & Median (percentile) & $28.18( \pm 7.36)$ years \\
\hline Monthly income in ETB & Median (percentile) & $1917(1427,2250)$ \\
\hline \multirow[t]{4}{*}{ Matrimonial Status } & Single & $208(56.7)$ \\
\hline & Married & $154(42)$ \\
\hline & Widowed & $3(0.8)$ \\
\hline & Others* & $2(0.5)$ \\
\hline \multirow[t]{4}{*}{ Education } & Diploma & $179(48.8)$ \\
\hline & $\mathrm{BSc}$ & $174(47.4)$ \\
\hline & Masters & $6(1.6)$ \\
\hline & Others** & $8(2.2)$ \\
\hline \multirow[t]{7}{*}{ Profession } & Nurse & $249(67.8)$ \\
\hline & Midwifery & $29(7.9)$ \\
\hline & Pharmacy & $23(6.3)$ \\
\hline & Laboratory & $22(6)$ \\
\hline & Medical Doctors & $19(5.2)$ \\
\hline & Health Officer & $10(2.7)$ \\
\hline & Other*** & $15(4.1)$ \\
\hline \multirow[t]{2}{*}{ Family Size } & $<=5$ & $328(89.4)$ \\
\hline & $>5$ & $39(10.6)$ \\
\hline \multirow[t]{3}{*}{ Total work experience } & $<=5$ years & $252(68.7)$ \\
\hline & $5-10$ years & $63(17.2)$ \\
\hline & $>5$ years & $52(14.2)$ \\
\hline \multirow[t]{3}{*}{ Experience in current work place } & $<=5$ years & $291(79.3)$ \\
\hline & $5-10$ years & $46(12.5)$ \\
\hline & $>5$ years & $30(8.2)$ \\
\hline \multirow[t]{3}{*}{ Employment status } & Full time & $339(92.4)$ \\
\hline & Part time & $22(5.9)$ \\
\hline & Contract & $6(1.6)$ \\
\hline \multirow[t]{2}{*}{ Position } & Staff & $358(97.5)$ \\
\hline & Head/coordinator & $9(2.5)$ \\
\hline
\end{tabular}

*Divorced, casual partner, ** Laboratory technician, druggist, health assistant ***Radiologist, dentistry, anesthis partthesia, environmental health, biomedical 
Staff Retention Activities: Almost all of the institutions reported the availability of staff appraisal plan, nevertheless, the documents were not observed at the time of data collection. It was also reported that the managing body conducted performance appraisal for staff members yearly and gave feedbacks after the appraisal. However, one of the study institutions failed to do so for fear of increasing staff complaints. The managing body also took disciplinary measures and counseling. Regarding staff involvement in planning organizational goals and strategies, the managers perceived as it was of medium rate. The managing body's practice in motivating staffs through financial incentives was rated as insufficient but medium for non-financial incentives. In addition, the managing body's effectiveness in decision making when problems encountered was rated as medium. And the working environment was moderately conducive.

Besides, absence of continuous development of HWs' skill and knowledge $(51.5 \%)$, absence of training continually coordinated, implemented and monitored $(64.6 \%)$, and absence of satisfaction assessment $(47.4 \%)$ were some of the reasons for frustrating the staff retention. All these three reasons were supported by qualitative data gained from head of the health centers and chief executive officer. About $40 \%$ of the study particiapnts depiected the presence of plans and programs of occupational health and safety policies.
Job Satisfaction: Five subscales having different items were used to measure the work satisfaction. Institutional scale had five items with 0.8 Cronbatch's alpha of internal consistency and a mean of 4.1. The second scale was job factor having 8 items with 0.8 Cronbatch's alpha and a mean of 3.4. The mean and Cronbatch's alpha for the 7 items of management scale were 0.9 and 3.2 respectively. The fourth scale was organizational factor with 11 items having 0.9 Cronbatch's alpha and a mean of 2.8. The last scale called environmental factor had 10 items, and its internal consistency and mean were 0.7 and 3.3 respectively. The overall health workers' satisfaction was marginally neutral (mean 3.3), but institutional factors were the top factors with which they were satisfied $($ mean $=4.1)$. However, health workers were marginally dissatisfied for organizational factors with mean of 2.8 .

Stuff Turnover: In five years period (September 2009 - August 2014), 45.9\% (331/721) of staffs had left their institutions. The highest percentage of turnover was registered in the 2001/2012 academic years accounting for $30.1 \%$ (Figure 1), and the turnover was by far more in hospitals than health centers. Professionally, general practitioners [GPs] (38.1\%), health officers [Hos] $(19.4 \%)$, medical doctors [MD] specialists (19.3\%), pharmacist $(14.3 \%)$ and nurses $(13.4 \%)$ were among the top five professionals (total number of respective health professional was the denominator) who left in the last five years (Figure 2). 


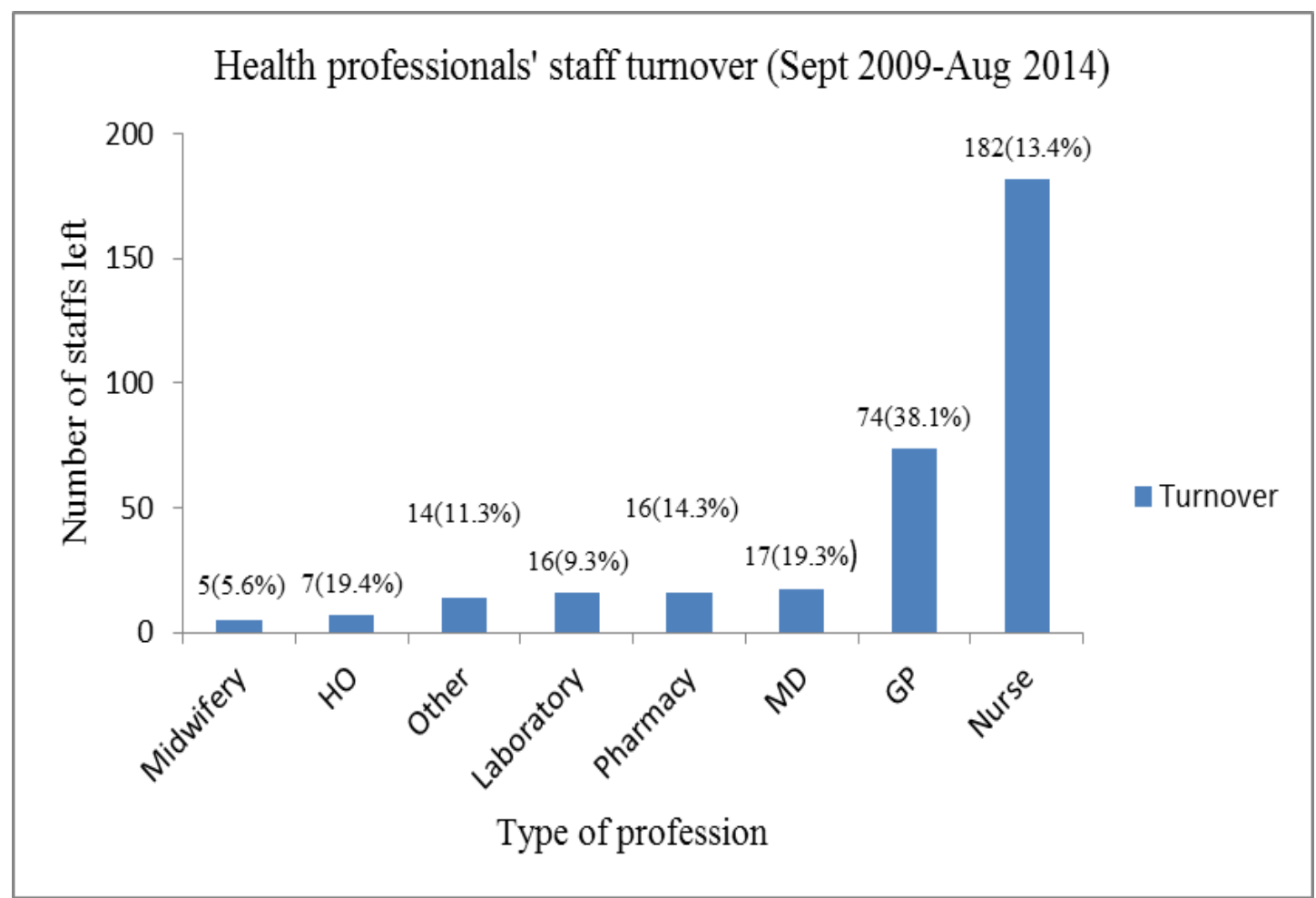

Other: Anesthesia, Biomedical Engineering, Environmental Health, Ophthalmology, Physiotherapy, Radiology Figure 1: Health professionals' staff turnover (Sept 2009-August 2014) by academic year in southwest Ethiopia, 2014

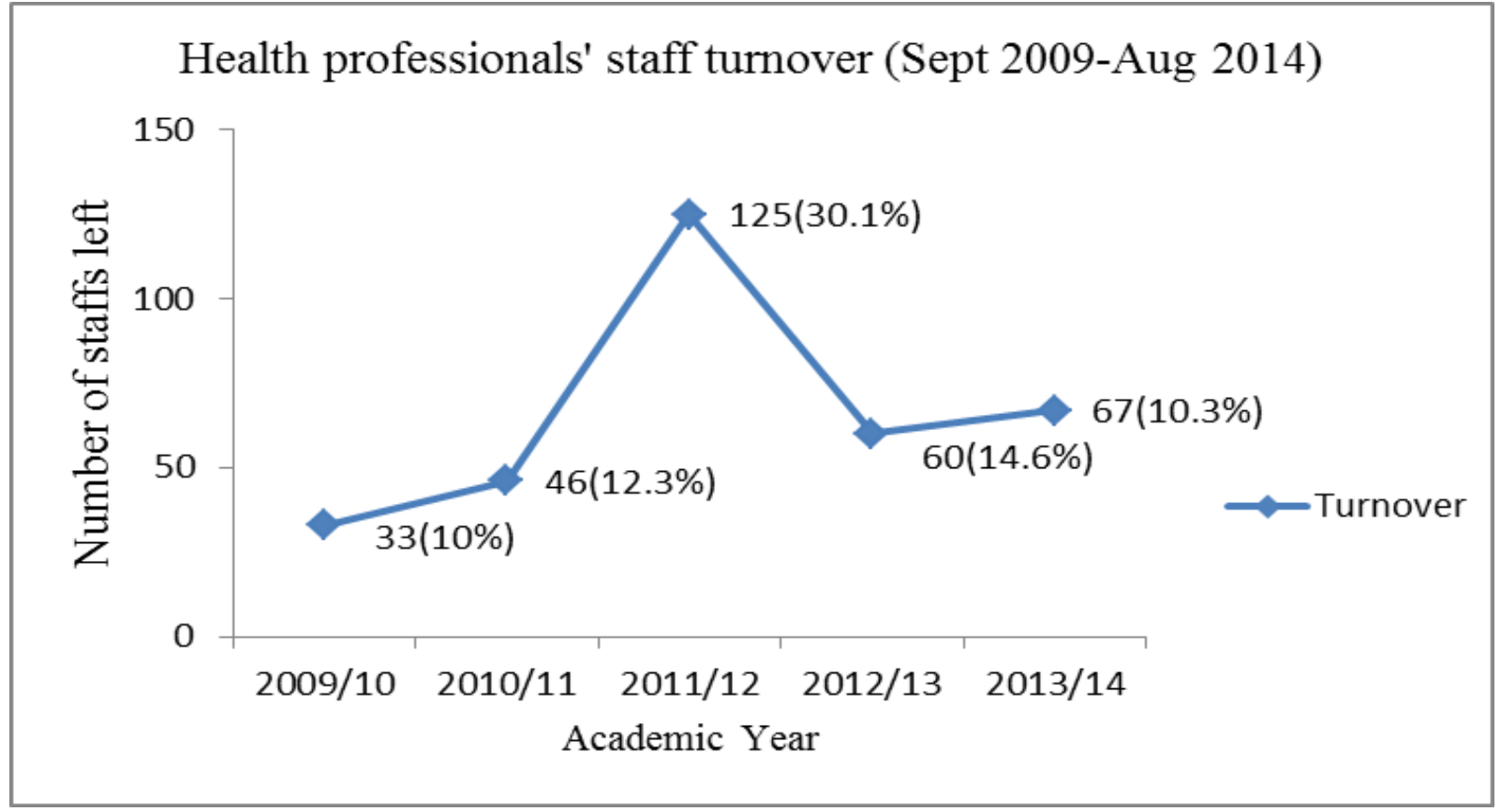

Figure 2: Health professionals' staff Turnover (Sept 2009-August 2014) by profession in southwest Ethiopia, 2014 
According to the $\mathrm{CEO} /$ head of health center report, though not high, there was staff turnover and the reasons for this were lack of incentives/fringe benefits, non-conducive environment, unsuitable weather of living environment and lack of scholarship opurtuities. Of course, the staff retention strategy was also reported to be medium.

Intention to Leave: In relation to intention to leave, more than half $(59.4 \%)$ of the health professionals had intended to leave for different reasons, and most of them wanted to leave after $1(49.8 \%)$ and $2(31.8 \%)$ years. Nurses and midwives were likely to intend to leave constituting $65 \%$ and $7.8 \%$ respectively. In terms of work experience, those who stayed for
5 years and below in work were more mlikely to intend to leave $(71 \%)$ than those who served for $5-10$ years $(18 \%)$ and more than 10 years $(11 \%)$. Age, ethnicity, total work experience, family size, job requirement, orientation, selection, gender, skill, overall satisfaction, institutional satisfaction, environmental satisfaction, job satisfaction, management satisfaction and organizational satisfaction were the candidate variables for multiple logistic regression. After checking for confounding, interaction and multicollinearity, gender, overall satisfaction, institutional satisfaction and organizational satisfaction were independently associated factors with intention to leave (Table 2).

Table 2: Factors independently associated with intention to leave among health workers in Southwest Ethiopia, 2014.

\begin{tabular}{|c|c|c|c|c|c|}
\hline \multirow[t]{2}{*}{ Variable } & & \multicolumn{4}{|c|}{ Intention to leave, $\mathbf{n}(\%)$} \\
\hline & & Yes & No & $\operatorname{COR}(95 \% \mathrm{CI})$ & AOR (95\% CI) \\
\hline Sex & $\begin{array}{l}\text { Male } \\
\text { Female }\end{array}$ & $\begin{array}{l}135(62.2) \\
82(37.8)\end{array}$ & $\begin{array}{l}75(50.3) \\
74(49.7)\end{array}$ & $\begin{array}{l}1.6(1.05-2.5)^{*} \\
1\end{array}$ & $\begin{array}{l}1.6(1.001-2.5)^{*} \\
1\end{array}$ \\
\hline $\begin{array}{l}\text { Over all } \\
\text { satisfaction }\end{array}$ & $\begin{array}{l}\text { Yes } \\
\text { No } \\
\text { I don't know }\end{array}$ & $\begin{array}{l}74(33.9) \\
114(52.3) \\
30(13.8)\end{array}$ & $\begin{array}{l}51(34.2) \\
60(40.3) \\
38(25.5)\end{array}$ & $\begin{array}{l}0.8(0.5-1.2) \\
1 \\
0.4(0.2-0.7)^{*}\end{array}$ & $\begin{array}{l}1.1(0.7-1.9) \\
1 \\
0.5(0.2-0.8)^{*}\end{array}$ \\
\hline $\begin{array}{l}\text { Organizational } \\
\text { satisfaction }\end{array}$ & $\begin{array}{l}\text { Below mean }(31.24) \\
\text { Above mean }(31.24)\end{array}$ & $\begin{array}{l}123(56.4) \\
95(43.6)\end{array}$ & $\begin{array}{l}56(37.6) \\
93(62.4)\end{array}$ & $\begin{array}{l}2.2(1.4-3.3)^{*} \\
1\end{array}$ & $\begin{array}{l}1.8(1.08-2.8)^{*} \\
1\end{array}$ \\
\hline $\begin{array}{l}\text { Institutional } \\
\text { satisfaction }\end{array}$ & $\begin{array}{l}\text { Below mean }(20.63) \\
\text { Above mean }(20.63)\end{array}$ & $\begin{array}{l}109(50) \\
109(50)\end{array}$ & $\begin{array}{l}57(38.3) \\
92(61.7)\end{array}$ & $\begin{array}{l}1.6(1.05-2.5)^{*} \\
1\end{array}$ & $\begin{array}{l}1.7(1.06-2.7)^{*} \\
1\end{array}$ \\
\hline Skill & $\begin{array}{l}\text { Skillful } \\
\text { Not skillful } \\
\text { I don't know }\end{array}$ & $\begin{array}{l}124(56.9) \\
22(10.1) \\
72(33)\end{array}$ & $\begin{array}{l}97(65.1) \\
19(12.8) \\
33(22.1)\end{array}$ & $\begin{array}{l}1 \\
0.9(0.4-1.8) \\
1.7(1.04-2.8)^{*}\end{array}$ & $\begin{array}{l}1 \\
0.7(0.3-1.3) \\
1.5(0.9-2.7)\end{array}$ \\
\hline $\begin{array}{l}\text { Established job } \\
\text { requirement in } \\
\text { the organization }\end{array}$ & $\begin{array}{l}\text { Yes } \\
\text { No } \\
\text { I don't know }\end{array}$ & $\begin{array}{l}111(50.9) \\
88(40.4) \\
19(8.7)\end{array}$ & $\begin{array}{l}87(58.4) \\
39(26.2) \\
23(15.4)\end{array}$ & $\begin{array}{l}1 \\
1.8(1.1-2.8)^{*} \\
0.7(0.3-1.3)\end{array}$ & $\begin{array}{l}1 \\
1.5(0.9-2.5) \\
0.5(0.2-1.2)\end{array}$ \\
\hline
\end{tabular}

* Stands for statistically significant values at P-value below 0.05

COR: crude odds ratio; AOR: adjusted odds ratio; CI: confidence interval 
Males were nearly 2 times ( $\mathrm{AOR}=1.6,95 \% \mathrm{CI}$ : 1.0-2.5) more likely to intend to leave than females. Health professionals who were neutral about their overall satisfaction were nearly $50 \%$ less to intend to leave than those who were satisfied $\quad(\mathrm{AOR}=0.5, \quad 95 \% \mathrm{CI}$ : $0.2-0.8)$. Specifically, health professionals with below mean score of institutional satisfaction were 1.7 times (AOR $=1.7,95 \% \mathrm{CI}$ : $1.06-2.7)$ more likely to intent to leave than their counterparts. Similarly, the odds of intention to leave among health workers with below mean score of organizational satisfaction were 1.8 more than $(\mathrm{AOR}=1.8,95 \% \mathrm{CI}: 1.08-2.8)$ than those with above mean score.

\section{DISCUSSION}

Job satisfaction is one of the most important factors in improving the productivity and quality of health services provided to clients and retaining workforce in the health sector. In this study, the participants reported that there was biannual staff appraisal and feedback, and counseling and disciplinary measures. However, had it been effected appropriately, poor management problem would have not been among the reasons for intention to leave, which is discussed below. This mismatch indicates that the management should improve practices in these areas. The status of financial incentives and working environment was rated as insufficient. This finding is similar with global experience and thus reminds that the management bodies at different levels should work hard for improving result oriented financial incentives and quality of the working environment to the best of their capacity.

In this study, $34.1 \%$ of the participants reported that they were satisfied with their current job. This result is, more or less, similar to nurses' satisfaction in Nigeria that showed $67.1 \%$ were less satisfied (6). The difference might be due to the difference in the scope of professionals and working environments in the study areas. Nevertheless, the result showed that the dissatisfied portion of professionals takes a significant proportion that requires managerial action to improve the situation. Although there is no much difference among the four studied satisfaction item in this study, much lower dissatisfaction towards organizational factors can be a signal for poor organizing capacity of the management bodies in motivating the professionals to the acceptable level.

The turnover rate of $45.9 \%$ in this study is somehow higher than some of the sub-Saharan African countries experiences (15). Such high attrition of skilled workforce can cause understaffing in the public health services. Salary differentials between public employment and other options around and abroad, physical working environment and unresponsive management practices could be among the factors that compel the health workers to leave the public health sector as happens in other subSaharan countries. Although the government is increasing salaries in fairly frequent intervals at its capacity, there is no independent evidence of its impact on turnover. It requires use various retention strategies focused on good management and leadership practices including open employees-management communication, skillful and supportive supervision, responsive management, employee recognition and clear sharing of responsibility with right accountability structure.

Moreover, $59.4 \%$ of the study participants reported that they intended to leave their current institution. This indicates that more than half of the health workforce were performing their task with half-heart intending to leave for better job or working condition. This finding is higher than the result of a study conducted in Ugandan that showed a little fewer than half (46\%) staffs intended to leave for local and abroad careers sooner or later (16). This result might be overstated or understated due to survivors' bias.

Intention to leave was varied by gender, overall satisfaction, institutional satisfaction and organizational satisfaction. Males were nearly 2 times more likely to intend to leave than females. This was similar with the study from Malawi that reported $52.1 \%$ of males intended to leave, but different from the studies conducted in Tanzania and South Africa that documented that $68.2 \%$ and $77 \%$ of females intended to leave (17). Intention to leave was also associated with job satisfaction, and this was similar with studies conducted in Saudi-Arabia (18).

More nurses and midwives (65\%) intended to leave than any other professionals. This is 
different from the historical findings of health workforce turnover in Ethiopia that showed doctors tend to migrate more than any other professionals. This unusual finding might be related to less number of doctors in relation to nurses and midwives in this study. In terms of experience, those with less than five years work experience $(71 \%)$ had higher intention to leave than those who served for more than 5 years (11$18 \%)$. This finding is consistent with other African experiences (15). Although it may be difficult to change this situation until the paying capacity matches with the average international market; the management should restrict leaving of professionals before completing nationally agreed public service while improving the managerial strategies to retain skilled HWF.

In conclusion, the overall health workers' satisfaction was marginally neutral, however, health workers' satisfaction related with organizational factors was disastasfied. Low salary, unfair management and distance from family were the major reasons. With regard to staff turnover, a considerable number staffs left over five years for a cause, and GPs from profession and hospitals from institution took the lead. More than half of the staffs intended to leave, and gender, overall satisfaction, institutional satisfaction and organizational satisfaction affected it. Thus, it is recommended that the concerned authorities should design strategies to improve the situation.

\section{REFERENCES}

1. Awofeso N. Improving health workforce recruitment and retention in rural and remote regions of Nigeria. Rural and remote Health, 2010; 10:1319.

2. Anyanwu JC. Rural Poverity in Nigeria: profile, determinants and exit paths. African Development Review, 2006; 17: 435-460.

3. Sindiwsa V. Staff Turnover at Selected South African Government Hospitals. Master's thesis. 2009.

4. DHSSPS. Northern Ireland Health and Social Care Workforce Census. Her Majesty's Stationery Office. 2012; 12.

5. David S, Jonathan C. United Kingdom (Scotland) health system review. Health system in transition, 2012; 14(9):130.

6. Ayamolowo SJ, Irinoye O, Oladoyin MA. Job Satisfaction and Work Environment of Primary Health Care Nurses in Ekiti State, Nigeria: an Exploratory Study. International Journal of Caring Sciences, 2013; 6:3.

7. Hailu et al. Turnover rate of academic faculty at the College of Health Sciences, Addis Ababa University: a 20-year analysis (1991 to 2011). Human Resources for Health. 2013; 11:61.

8. Shields MA, Ward M. Improving nurse retention in the National Health Service in England: the impact of job satisfaction on intentions to quit. $J$ Health Econ, 2001; 20: 677-70.

9. Price JL, Mueller CW. A causal model of turnover for nurses. Acad Manag J, 1981; 24: 543-65.

10. Lu H, While AE, Barriball KL. Job satisfaction among nurses: a literature review. International J Nurs Stu, 2005; 42: 211-27.

11. Blegen MA. Nurses' job satisfaction: a meta-analysis of related variables. Nurs Res, 1993; 42: 36-41.

12. Zangaro GA, Soeken KL. A meta-analysis of studies of nurses' job satisfaction. Res Nurs Health, 2007; 30: 445-58.

13. Hayes B, Bonner A, Pryor J. Factors contributing to nurse job satisfaction in the acute hospital setting: a review of recent literature. J Nurs Manag, 2010; 18: 804-14. 
14. CSA. Population and Housing Census Report: Ethiopia. Central Statistical Agency 2007.

15. Antwi J and Phillips D. Wages and Health Worker Retention In Ghana. Evidence from Public Sector Wage Reforms. 2012

16. Ministry of Health. The Republic of Uganda Health Workforce Study: Satisfaction and Intent to Stay Among Current Health Workers. 2006.

17. Duane Blaauw, Prudence Ditlopo, Fresier Maseko, Maureen Chirwa, Aziza Mwisongo, Posy Bidwell, Steve Thomas and Charles Normand. Comparing the job satisfaction and intention to leave of different categories of health workers in Tanzania, Malawi, and South Africa. Glob Health Action. 2013; 6: 127-137.

18. Salman HAlsaqri. A Survey of Intention to Leave, Job Stress, Burnout and Job Satisfaction among Nurses Employed in the Ha'il Region's Hospitals in Saudi Arabia. PhD thesis. 2014. 